\title{
An integrated approach to understanding the role of the long neck in plesiosaurs
}

Leslie F. Noè, Michael A. Taylor, and Marcela Gómez-Pérez

Acta Palaeontologica Polonica 62 (1), 2017: 137-162 doi:https://doi.org/10.4202/app.00334.2016

The evolution and function of the long neck in plesiosaurs, and how the problems associated with stiffness or flexibility were overcome during feeding, or rapid swimming during predator avoidance, are explored, and a new interpretation for the function of the plesiosaur neck is presented. Based on the anatomy of the articular faces of contiguous cervical vertebral centra, neural arches, and cervical ribs, the plesiosaur neck was mainly adapted for ventral bending, with dorsal, lateral and rotational movements all relatively restricted. Predominant ventral bending indicates the neck was adapted for use beneath the body, suggesting feeding in the water column, close to the sea floor, or within soft sediments on the sea floor. A new model is proposed for the plesiosaur bauplan, comprising the head as a filter, straining, sieve feeding or sediment raking apparatus, mounted on a neck which acted as a stiff but ventrally flexible feeding tube, attached to the body which acted as a highly mobile feeding platform. Numerous features of plesiosaurs, including cranial and dental form, cervical vertebral morphology, body shape and limb-based propulsion, conform to this model. Comparative data from modern organisms support this novel explanation for the structure and function of the plesiosaur long neck. This integrative analysis offers an explanation for the evolution of the plesiosaur long neck as a key evolutionary novelty, and why this apparently enigmatic feature remained a prominent feature of plesiosaurs throughout their long evolutionary history.

Key words: Sauropterygia, Plesiosauria, long neck, functional anatomy, filter feeding, palaeoecology, evolution.

Leslie F. Noè [1.noe@ uniandes.edu.co], Departamento de Geociencias, Universidad de los Andes, Cra 1 No 18A-10, AA 4976, Bogotá D.C., Colombia (ORCID http://orcid.org/0000-0003-2676-3316). Michael A. Taylor [mat22@le.ac.uk], Department of Natural Sciences, National Museums Scotland, Chambers St., Edinburgh EH1 1JF, Scotland, and School of Museum Studies, University of Leicester, England (ORCID http://orcid.org/0000-0002-1495-8215). Marcela Gómez-Pérez [mgomezperez@cantab.net], Departamento de Geociencias, Universidad de los Andes, Cra 1 No 18A-10, AA 4976, Bogotá D.C., Colombia; current address: Museo Geológico José Royo y Gómez, Servicio Geológico Colombiano, Diagonal 53 No. 34-53, Bogotá D.C., Colombia (ORCID http://orcid.org/0000-0002-0630-2435). 
This is an open-access article distributed under the terms of the Creative Commons Attribution License (for details please see creativecommons.org), which permits unrestricted use, distribution, and reproduction in any medium, provided the original author and source are credited.

FaF $\underline{\text { Full text }(1,188.4 \mathrm{kB})}$ 